\title{
GÊNERO, SEXUALIDADE E ENVELHECIMENTO: Miradas pós-críticas na educação e/m saúde ${ }^{1}$
}

\author{
Fernando Altair Pocahy*
}

\begin{abstract}
Resumo: O texto apresenta as contribuições do GEERGE para o debate educacional e/m saúde sobre as intersecções entre gênero, sexualidade e envelhecimento. $\mathrm{O}$ trabalho em tela foi produzido desde miradas pós-críticas articuladas aos estudos feministas e queer, informando problematizações sobre a produção da diferença e o trabalho das pedagogias culturais. O corpus empírico da composição deste ensaio recorre a teses, dissertações e estudos produzidos por integrantes do grupo de pesquisa. Os resultados apontam para o protagonismo desse coletivo de pesquisa na articulação entre envelhecimento, gênero e sexualidade. A aposta central do trabalho é de que o conjunto de trabalhos emergiu de forma difusa, mas balizado pelas posições ético-epistemológicas assumidas pelo grupo na pesquisa sobre gênero e sexualidade no campo educacional.
\end{abstract}

Palavras-chaves:Gênero, Sexualidade, Envelhecimento

GENDER, SEXUALITY AND AGEING: Post-critical views on education and health

\begin{abstract}
This essay aims to present GEERGE's contributions to the educational debate about health and the intersections between gender, sexuality and ageing. The work presented here originates from post-critical views articulated to feminist and queer studies, and communicates the problematizations about the production of difference and the work of cultural pedagogies. The empirical corpus of this essay resorts to theses, dissertations and studies produced by members of the research group. The results point to the important role of this research collective in the articulation between aging, gender and sexuality. The central focus of the study is that the set of papers emerged in a diffused way, but based on the ethical-epistemological positions assumed by the group regarding the research on gender and sexuality in the educational field.
\end{abstract}

Keywords: Gender, Sexuality, Ageing

Submissão21-10-18 Aceite 10-06-19

\section{CONTEXTOS E POLÍTICAS: UMA INTRODUÇÃO}

Este ensaio cartografa algo da produção de pesquisas sobre envelhecimento em intersecção com gênero e sexualidade no campo da educação e/m saúde ${ }^{2}$. A rota de minhas problematizações privilegia a emergência desse tema no GEERGE - Grupo de Estudos em Educação e Relações de Gênero. Destaco o protagonismo do grupo nessa articulação de pesquisa e dirijo uma aposta sobre as condições de possibilidade para a produção de determinados objetos / problemas de pesquisa. A aposta em cartografar algo dessa produção em torno do envelhecimento seguirá igualmente o rastro das interlocuções pós-estruturalistas que pautam e problematizam as noções de diferença

\footnotetext{
${ }^{1}$ Este trabalho contou com o apoio de recursos do CNPq (Edital Universal 2018) e da FAPERJ (JCNE 2019).

*Professor da Faculdade de Educação, Departamento de Estudos Aplicados ao Ensino, Programa de Pós-Graduação em Educação da Universidade do Estado do Rio de Janeiro - UERJ, Coordenador do Geni - Grupo de Estudos em Gênero, Sexualidade e/m Interseccionalidades na Educação e/m Saúde.

${ }^{2}$ Esse jogo de palavras educação e/m saúde advém de apostas de Dagmar Estermann Meyer (2014), aqui como esse híbrido entre as práticas de educação e da saúde, ao mesmo tempo em que se preservam em contextos estratégicos a autonomia dos campos de atuação.
} 
e discurso na educação e/m saúde. O objetivo do trabalho é compor um mapa (processual) sobre as redes e os fluxos sociais - os diagramas de correlações de forças, os diagramas de saber-poder - que, ao ligarem-se ou se intersectarem, produziram as condições de possibilidade para a emergência do envelhecimento como objeto a ser pensado nas tramas do gênero e da sexualidade e em suas interseções com outros marcadores

A cartografia tem por objetivo aqui ampliar os traçados de problematização sobre "relações de naturezas diversas, formas circulantes de subjetividade, agenciamentos do desejo, práticas de objetivação e sujeição, modos de subjetivação e assujeitamento, práticas de resistência e de liberdade, ou mesmo formas históricas de estetização e produção de si mesmo.”(PRADO FILHO; TETI, 2013, p. 57). Em síntese, minha aposta é a de que, ao acompanharmos determinadas relações e práticas sociais com a pesquisa estamos igualmente produzindo modos de produção de sentido e de subjetividade, ao mesmo tempo em que igualmente nos tornamos sujeitos de/ em discurso. Portanto, cartografar a produção de pesquisa é acompanhar os agenciamentos e as políticas de afecção que nos constituem (ROLNIK, 2011). Busco dessa forma problematizar como algo se constitui como um objeto a ser pensado, conhecido e governado

O conjunto dos trabalhos que compõem essa cartografia da produção do tema do envelhecimento no GEERGE, embora não indique que esse estivesse vinculado a um programa continuado de pesquisas (como um projeto eixo ou linha de pesquisa), aconteceu de forma simultânea no grupo e em momento onde a intersecção específica sexualidade-gênero- envelhecimento ainda não havia se consolidado no cenário da pesquisa e intervenção-social nacional e, tampouco, no contexto da educação. Esse fato coloca o GEERGE e pesquisador $x \mathrm{~s}^{3}$ e ele vinculad $x$ s em posição pioneira.

Porém, a afirmação do tema evidencia mais do que isso. Ela aponta para a produção da diferença como um jogo teórico-performativo, como podemos acompanhar a partir das problematizações empreendidas por Tomaz Tadeu da Silva (1999). Isto é, as apostas no envelhecimento como objeto / problema de pesquisa seguiram no rastro

\footnotetext{
${ }^{3}$ Faço uso do sinal «x» como forma de colocar sob rasura noções consagradas e inflexões binárias de gênero. A noção de que certos conceitos, expressões, noções 'não servem mais - não são mais 'bons para pensar' - em sua forma original, não reconstruída." (HALL, 2001, p. 104). Portanto, mais do que fazer caber múltiplos gêneros ou posições de sexualidade através de sinais como o próprio X ou @, *, \#, _, 'e', etc, tento com essa rasura linguística evidenciar que a gramática marca a diferença. Não se trata de uma forma inclusiva, embora guarde essa potencialidade, mas justamente desejo expor que a linguagem não somente não é neutra, mas que corresponde a uma arena de disputa sobre regimes de visibilidade que se articulam vivamente na produção e na marcação da diferença. Ao mesmo instante, introduz-se aqui uma materialidade estética (estilística do signo e do sinal) que corresponde de uma disposição ética, abrindo os termos de uma agonística (política) da/na/com a língua.
} 
das articulações ético-epistemológicas pós-críticas em educação, traçando um corpus analítico que tomou o corpo como arena da diferença. Desse modo tematização do envelhecimento vem na esteira dos estudos sobre corpo que já ocupavam interesse de pesquisas. Mas ela é mais contingenciada pela disposição de abertura do que propriamente uma linha de investigação.

Acompanhando a intensa movimentação ético-epistemológica dos fluxos de produção de diferença (em uma aproximação entre esforços teóricos e contingências sociais), o tema do envelhecimento surgiu inicialmente mais como contingência política e cultural sobre a diferença (engendrada em um movimento pós-crítico de pesquisa) do que propriamente uma programática ou pragmática em pesquisa. Desde sua fundação o GEERGE produziu articulações balizadas por compromisso ético-epistemológico em intensa interlocução com os estudos feministas e, não muito depois, com os estudos queer.

Se, de alguma forma, adultos jovens ou adultos médios ocupavam lugar nas pesquisas, refere Guacira Lopes Louro (em conversa informal), as pontas geracionais ainda eram desafio. Juventudes e infâncias, pela relação com a educação escolar não se demoraram a ocupar foco de investigação. Porém, a velhice, demorou-se a chegar.

Como tudo isso evidencia, ampliaram-se não apenas os interesses de pesquisa em sua relação direta com gênero e sexualidade no campo educacional (inicialmente mais escolar), mas os modos de subjetivar (a pesquisa ela como prática de subjetivação), engendrados na produção de problemas de/em pesquisa que não eram feitos apenas de objetos ou teorias. Afirma Guacira Lopes Louro (1997), fundadora do grupo:

O GEERGE - Grupo de Estudos de Educação e Relações de Gênero — que "inventamos" há alguns anos atrás, representa o "lugar" mais constante das perguntas, da construção dos problemas e do aprofundamento dos estudos. Mas o GEERGE, longe de ser uma entidade abstrata, é gente: Dagmar, Tânia, Rosângela, Jane, Nara, Alex. Parceiras e parceiro de muitas tardes de discussão acalorada, de sentidos impasses teóricos e da construção de uma estreita amizade. Ali não se sabe (e também não importa) quem faz as perguntas, quem provoca o debate, quem discorda ou tem uma idéia notável: somos um grupo. (p. 11)

O registro de Guacira está em consonância com as miradas pós-críticas em educação (SILVA, 1999) que anunciam (e enunciam) não apenas uma crítica à neutralidade científica, mas aquelas proposições que sustentam o caráter performativo das teorias e a consequente postura de se colocar sob suspeita e duvidar das certezas (verdades - os achados de pesquisa, os dados, os procedimentos, as prescrições). 
Efetivamente trata-se de uma posição que olha com desconfiança e, por vezes, em franco estranhamento com proclamadas verdades ou cânones. A crítica às metateorias encontra aqui força e destaque, afirmando que nesse jogo que reconhece o discurso como baliza epistemológica, os sujeitos, que dele participam, têm lugar central (através de suas marcas). Como afirma Louro (1997): o grupo, a pesquisa, tudo isso é feito de gente. Sujeitos com suas marcas, com suas implicações ético-políticas, com seus desejos, com suas formas de experimentar o mundo e produzir política, conhecimento, arte, vida... educação e saúde.

No rastro das problematizações pós-críticas é importante notar que a noção de poder passa a ser descentrada, ele está em todos os espaços-tempos da vida e é operado e opera sobre e com os sujeitos, conduzindo- $x$ s a certas posições (forjadas e/ou engendradas). Ou seja, ao tomar o poder como rede e não como unidade de centralidade (como O Estado ou A Política, A Instituição, etc.), coloca-se em cena múltiplos agenciamentos e sujeitos nos jogos de dominação e nas formas de governamento. Silva (1999) corrobora essa aposta ao afirmar que a partir das abordagens das teorias (pós-críticas), o mapa do poder é ampliado para incluir os processos de dominação centrados na raça, na etnia, no gênero e na sexualidade.

É desde essa rede complexa dos processos de subjetivação que a pesquisa aparece como figura importante nos mapas dos modos de governar (a si e aos outros). Acompanhando as apostas pós-críticas, ainda em diálogo com Silva (1999), a teoria não se limitaria a partir de agora a descobrir, descrever e/ou explicar a realidade (em todo caso, as realidades); ela estaria envolvida fortemente na produção dos objetos que descreve, daquilo sobre o que fala.

É, pois, desde essa linha de reflexividade ético-epistemológica que o trabalho do GEERGE, fundado em 1991, e a proposição da Linha de Pesquisa Educação, Sexualidade e Relações de Gênero em 2000, encontra profícua articulação com diferentes interesses de pesquisa sobre as relações de saber-poder que cercam o corpo, o gênero e a sexualidade. Assume-se que nenhum gesto em pesquisa é desinteressado e que está-se sempre imerso em relações de saber-poder e em movimentos para o governo de si ou de outrem. Irremediavelmente estamos produzindo a diferença, independente de nossos posicionamentos políticos.

No entanto, para ess $x$ s pesquisador $x$ s (pós-)críticos, o que se coloca como horizonte é justamente a possibilidade de avaliarmos esses jogos com alguma margem de liberdade. E é através da produção continuada de práticas de liberdade na produção 
de teorização que se possibilita o alargamento dos horizontes da dúvida e da contestação. Dessas condições para o exercício ético-político da pesquisa emergem, entre outras posições, aquela de que pesquisa-se com $x$ s outrxs e não sobre xs outrxs. Nesse momento abre-se, portanto, a possibilidade de agenciamentos coletivos de enunciação, efeito do convite a que tantxs outrxs participem dessa agonística da produção do conhecimento que é igualmente produção de subjetividade - e está inserida em novos jogos de verdade (contestando alguns, sucumbindo a outros).

É nesse sentido que discussões transversalizadas por distintas áreas do conhecimento foram se constituindo em intensas apostas e diálogos no GEERGE, ampliando o escopo analítico da pesquisa com gênero e sexualidade na educação. Nesse mesmo movimento, a própria aposta nos sentidos e significados da educação foram assumindo novos contornos. A educação e o currículo (um dos objetos centrais para a política educacional) é lida-vivida em sentido ampliado e compreendida como uma prática de significação (Silva, 1999).

A diferença, objeto central das problematizações pós-estruturalistas e pós-modernas é, nos termos de Silva (1999), processo linguístico e discursivo. Ela não é natural; é, pois, discursivamente produzida. Isso consolidou a aposta em um modo de pensar-praticar estudos em educação como possibilidade de problematização sobre os modos de ensino-aprendizagem e as pedagogias envolvidas na constituição de si e os modos como nos tornamos sujeitos a partir das marcas da diferença (desse processo/fluxo a que chamamos diferença). Louro (2001) sinaliza um importante horizonte ético-epistemológico a mobilizar muitas de suas/ nossas inquietações no campo educacional, a partir das miradas pós-estruturalista em diálogo com os estudos feministas (muitos deles em abordagem pós-estrutural e pós-moderna) e que depois vieram a se ampliar com as abordagens queer:

(...) feministas e pós-estruturalistas compartilham das críticas aos sistemas explicativos globais da sociedade; apontam limitações ou incompletudes nas formas de organização e de compreensão do social abraçadas pelas esquerdas; problematizam os modos convencionais de produção e divulgação do que é admitido como ciência; questionam a concepção de um poder central e unificado regendo o todo social, etc. (p. 29).

As apostas em pesquisa em gênero, sexualidade e educação é assim vertiginosamente amplificada: novas análises e giros epistemológicos para a/na produção de objetos/ problemas de pesquisa passaram a emergir e novos sujeitos (pesquisadorxs elxs mesmxs marcados nos jogos mais dramáticos da diferença, 
ali onde ela e capturada pelos signos da identidade ou mesmo quando se torna letal) se aproximam do grupo e do campo produzindo outras miradas. Minha aposta é de que isso ocorreu com o tema do envelhecimento em sua interseção com a sexualidade e gênero, objeto deste artigo.

Essa intensa produção não ficou apenas no interior do grupo. Cruzou fronteiras, mesmo próximas. A repercussão disso pode ser observada por Doll e colaboradoras (2015), também docente e discentes do Programa de Pós-Graduação em Educação da UFRGS, mas vinculados/as a outras linha de pesquisa. Elxs afirmam (em relação ao envelhecimento, tema central do grupo coordenado por Johannes Doll):

Atualmente, as identidades de gênero, sexualidade e etnia são temas centrais no campo da Educação. Em uma sociedade em rápido envelhecimento, onde até cinco gerações podem conviver numa mesma família, a constituição das identidades geracionais são problematizações imprescindíveis, que precisam entrar na pauta do debate educacional (p. 10-11).

Em face dessa observação, articulada ainda a outras apostas que trarei mais adiante, sigo convencido de que um dos fatores que podem ter colocado nosso grupo de pesquisa em protagonismo na abordagem do envelhecimento corresponde ao fato de que sua atuação esteve desde sempre interessada nas questões educacionais desde uma abordagem capaz de fazer emergir novas figuras de problematização e novos sujeitos na e com a pesquisa.

A abordagem pós-estruturalista foi potencializadora da aproximação de pesquisador $x$ s não somente do campo educacional (ainda mais voltado à escola e às políticas educacionais), mas também de outras áreas, em especial a saúde coletiva (e áreas parceiras como a enfermagem, fisioterapia, educação física e psicologia) e das militâncias em movimentos sociais, notadamente os de minorias sexuais e de gênero. Novas perguntas, novos problemas e outros modos de pesquisar vão se produzindo.

Mas há ainda que se destacar particularidades na composição de certos interesses de pesquisa no interior da discussão de gênero e sexualidade nesse encontro com sujeitos advindos de outros campos e frentes, como o caso do movimento social (já referido), por exemplo. A temática das minorias sexuais e de gênero já estava presente nas teorizações que compunham o corpus epistemológico do grupo. No entanto, a aproximação de sujeitos militantes e de profissionais de outros campos, como a saúde (e que já vinham em diálogo com os movimentos sociais, especialmente através da pauta da AIDS), ampliou o lastro de investigações produzidas no GEERGE.

Não tenho condições de abordar essa rica e complexa experiência e tampouco 
teria a presunção de mapear as tantas trajetórias e acontecimentos que compuseram a intensa produção ético-epistemológica que marca a(s) história(s) do grupo. Ousarei apenas articular algo em torno do lugar desde onde me movimentei em direção ao GEERGE. Esse lugar é a militância (dita) LGBT e algo de sua articulação com a saúde. De forma breve situarei um pouco dessas andanças que encontram referências mais detalhadas em outra publicação (POCAHY \& DORNELLES, 2017).

Em 2003, o grupo nuances ${ }^{4}$ - grupo pela livre expressão sexual, lançou em Porto Alegre uma campanha bastante ousada (retratando o cotidiano de gueis ${ }^{5}$ idosos em saunas), financiada com recursos da política de prevenção ao hiv/aids, colocando foco pela primeira vez no contexto nacional na figura dos idosos na cama-trama da homossexualidade. O alvo dessa campanha eram as 'bichas velhas' e a interpelação respondia a uma constatação: a frequência de muitos idosos em saunas e clubes, a circulação de alguns desses idosos nos eventos do nuances, as histórias do cotidiano da 'comunidade' na cidade e os muitos causos de golpe a que estavam submetidos (pelos bofes $^{6}$ ou mesmo por familiares), povoam o imaginário. Imagem não tão longínqua, por certo. Há que se fazer justiça às personagens da literatura, como A lenda das três Jaciras, conto de Caio Fernando de Abreu, narrativa por onde emerge a expressão Irene para se referir aos gueis idosos. Ou mesmo Sargento Garcia, conto envolvente entre um recruta e o milico.

De outra parte, o jornal do nuances implodia o armário da velhice: na coluna social É uó - onde a baixa sociedade dá o close, não faltavam ilustres figuras bailando no Era uma Vez, tradicional boate e 'casa' de prostituição. Michês (garotos de programa) e clientes (em sua maioria sujeitos acima de 50 anos) volta e meia causavam inveja em fotos de aniversários ou mesmo na premiação do consagrado concurso Miss Plenitude, voltado a bichas quinquagenárias que se produziam em trajes femininos apenas para o momento.

Nessa época a prevenção à aids ainda não estava impactada pelo recrudescimento

\footnotetext{
${ }^{4} \mathrm{O}$ grupo grafa em letras minúsculas seu nome como posicionamento político-linguístico-estético. O nuances surgiu em 1991 em Porto Alegre e mantém ativamente protagonista nos direitos humanos. A Parada Livre, evento criado no interior das ações do coletivo, é uma de suas mais exitosas práticas de atuação, entre tantos outros e inúmeros feitos em articulação com outros movimentos sociais e com a Universidade. O GEERGE foi parceiro do nuances em muitas ações, destacando-se o curso Educando para a Diversidade, dirigido a educadorxs das redes municipal e estadual de educação. Minha primeira aproximação com o nuances foi em 1996, ainda estudante de Psicologia na Universidade do Vale do Rio dos Sinos - Unisinos. E, até 2011, permaneci intensamente envolvido com as ações de coordenação política e de projetos do grupo.

${ }^{5}$ Essa é outra subversão e contestação linguística empreendida pelo nuances, abrasileirando a interpelação "gay" fortemente influenciada pelos contextos de países do norte.

${ }^{6}$ Termo êmico a designar homens, geralmente heterossexuais, garotos de programa ou sujeitos de pronunciada 'masculinidade'.
} 
nessa faixa etária, mas já era tomada com interesse e compromisso pelo grupo, especialmente porque muitos dos sujeitos nesses espaços já cruzaram décadas convivendo com o vírus ou mesmo com pessoas vivendo com o vírus. Era preciso dizer, portanto, Prazer não tem idade (título da campanha, ilustrada por Luis Gustavo Weiller); e a campanha do nuances foi 'visionária'. Somente anos mais tarde a epidemia estaria enredada com a velhice e o universo acadêmico se orientaria para esse objeto.

Em 2004 acompanhamos algo dessa discussão do campo acadêmico através de um ensaio de Julio Simões, docente e pesquisador da USP, sobre a questão do envelhecimento. Capítulo de livro publicado na coletânea intitulada Sexualidade e saberes: convenções e fronteiras organizada por Carrara e colaboradorxs (2004) o texto figura ainda em quase todos os trabalhos sobre o tema com força seminal. Porém, muito antes ainda, o trabalho de Veriano Terto Junior (1987), ao abordar as práticas sexuais em cinemas pornôs oferecera pistas importantes sobre a circulação de idosos nas redes de sociabilidades orgiásticas. Em sua dissertação ele não opera em problematizações com o objeto envelhecimento, mas ao referir a presença de tais sujeitos no campo (esses organizando de certo modo os espaços de sociabilidade), é considerado um dos textos pioneiros na composição da temática.

Demoraria-se ainda um pouco mais para que se notasse um volume maior de trabalhos de pesquisa (como teses e dissertações), alguns deles orientados pelo próprio Simões ou por sua parceira de trabalho Guita Debert (Unicamp), pioneira nos estudos sobre envelhecimento, a partir dos estudos feministas, da mesma forma que as ações no movimento social (notadamente o movimento aids ou, no caso do nuances, em articulação com as políticas de prevenção às ist/hiv e aids).

Foi assim que, década mais tarde, a ABIA - Associação Brasileira Interdisciplinar de Aids (ALMEIDA \& RAXACH, 2013) trouxe à pauta a discussão do envelhecimento e do hiv e aids, através do projeto $3^{\text {a }}$ Idade, homossexualidade e prevenção do hiv. O projeto foi lançado em 2012, já no interior de marco epidemiológico que impactara bastante o campo da prevenção e assistência. $\mathrm{O}$ número de idosos/as infectados pelo vírus estava aumentando. Par e passo ao número de jovens (gays) infectados. Além disso uma constatação importantíssima: as pessoas passavam a envelhecer com o vírus, passada a terceira década da epidemia.

Da saúde para a educação, e em direção não diametralmente oposta, é importante sublinhar, a partir das contribuições de trabalhos de Doll e colaboradoras (2015), que fez-se longa e intensa trajetória da produção do campo gerontológico no 
Brasil, especialmente a partir de atividades associativas e projetos de saúde.

No entanto, amarca heteronormativa (LOURO, 2009) fez sombra (ou mesmo apagara) as minorias sexuais e de gênero. Se desde 1970 temos no Brasil estudosintervenções sobre o tema do envelhecimento, foi somente a partir de 2004 que os sujeitos ditos dissidentes da heterossexualidade compulsória (RICH, 2010) passaram a ser enunciados como sujeitos e 'populações' passíveis de interesse para a pesquisa e intervenção.

As ações produzidas pelo SESC, iniciadas há quase 50 anos (Doll e colaboradoras, 2015) aparecem como uma dessas importantes balizas na constituição do campo em ações educativas para idosas e idosos pelo país, afirmam esses/essas os/as pesquisadores/as. Mesmo assim, e em que pese os estudos refletirem a presença massiva de mulheres idosas nessas intervenções e a ausência dos homens, pouca ou quase nenhuma preocupação com a sexualidade e o gênero tivera lugar pelo menos até os início do século XXI.

Em relação ao marcador gênero, a pesquisa brasileira inicia suas primeiras reflexões nas Ciências Sociais a partir dos trabalhos das antropólogas Guita Debert (Unicamp) e Alda Motta (UFBA). Porém, o cruzamento dos marcadores sexualidade, gênero e envelhecimento no campo amplo das Ciências Humanas e Sociais e, mais especificamente, no contexto educacional, demoram a se constituir objeto de pesquisa.

Os estudos iniciais sobre gênero e envelhecimento (em uma perspectiva de discussão sobre heteronormatividade ou heterossexualidade compulsória) não acompanharam a constituição e definição do campo de estudos sobre gênero e sexualidade na pesquisa brasileira; eles vieram na esteira, de forma mais lenta. Passadas pelas menos duas décadas depois da criação dos primeiros grupos sobre gênero e educação é que temos notícias das primeiras pesquisas articulando sexualidade e heteronormatividade. Esse fato é um dos elementos que me conduziram a pensar como se estabeleceu o interesse por esse objeto na pesquisa em educação e produzir este ensaio, que tem o GEERGE como figura importante nesse desenho do campo e na área.

\section{GERAÇÕES EM/DE PESQUISA}

A ambiência e o interesse por pesquisas com o marcador geracional não é uma evidência nova no GEERGE: Dagmar Estermann Meyer (1999) elaborou tese sobre a 
cultura teuto-brasileira-evangélica, a partir de documentos de referência nas comunidades gaúchas, notadamente produzidos por sujeitos adultos; Jane Felipe de Souza (2000), em suas pesquisas com as infâncias e trabalho docente; os estudos de masculinidades, com homens bissexuais adultos, realizado por Fernando Seffner (2003); os estudos sobre juventudes e sexualidades empregados por Rosângela Soares (2005); as personagens de produções dirigidas ao público infanto-juvenil, Ruth Sabat (2003); e o trabalho com adultos em formação em direitos humanos e segurança pública de Rosimeri Aquino Silva, (2007), apenas para citar alguns dos trabalhos de docentes que permanecem ligadxs ao grupo atualmente.

$\mathrm{Na}$ esteira dessa produção, muitos outros trabalhos, orientados por ess $x \mathrm{~s}$ professor $x$ s que atuam no GEERGE, compuseram esse amplo lastro de preocupação com a intersecção do marcador geracional, inicialmente com as infâncias e as juventudes. É nesse momento então, quando esses docentes passam igualmente a orientar trabalhos, assim como Guacira Lopes Louro, e que as pesquisas sobre envelhecimento florescem.

Em face do objeto deste artigo destaco a pesquisa de Luiz Fernando Alvarenga (2006; 2012) com idosas cisgênero ${ }^{7}$ e heterossexuais, o meu próprio trabalho (Fernando Pocahy, 2011) e de Gustavo Duarte (2013) com gays idosos como esses movimentos iniciais. Cabe ainda indicar que Dagmar Estermann Meyer (2011) e Guacira Lopes Louro (2011) também articularam ensaios com o tema do envelhecimento, muito possivelmente mobilizadas por essa nova leva de trabalhos que passaram a orientar. Com isso, observa-se, a idade ou o marcador geracional, passou a pesar (mais) e contribuir para as diferentes posições de sujeito que emergem na articulação com outros marcadores. Em minha tese (POCAHY, 2011) tive a oportunidade de afirmar que nesse horizonte a idade passa a ser compreendida como:

\footnotetext{
${ }^{7}$ A cisnorma é percebida aqui através da manutenção de privilégios dirigidos a pessoas supostamente consideradas coerentes ao sistema corpo-gênero (anátomo-gendradas). Essa posição teria como efeito regulatório e hierarquizador a interpelação abjeta e patologização da transexualidade - e mais amplamente da trangeneridade. Como afirma Leila Dumaresq citando Viviane Vergueiro (2014) a cisgeneridade pode ser entendida “(...) gêneros vistos como naturais, cisgêneros, pode significar uma virada descolonial no pensamento sobre identidades de gênero, ou seja, nomear cisgêneridade ou nomear homens-cis, mulheres-cis em oposição a outros termos usados anteriomente como mulher biológica, homem de verdade, homem normal, homem nascido homem, mulher nascida mulher, etc" (s/p). De outra parte, e em consonância às proposições supracitadas, recorro à ideia de hetero/cisnormatividade como forma de evidenciar os efeitos desses ideais regulatórios de gênero, que estariam associados à suposta naturalidade do corpo (através da linha de inteligibilidade corpo->gênero->sexualidade - uma matriz fundacional) e sua articulação com os privilégios daí decorrentes. Note-se com isso que a cisnormatividade também marcaria posições privilegiadas para aquelas pessoas que de alguma forma também poderiam ser consideradas desviantes (agora apenas do ponto de vista da sexualidade - ou 'orientação sexual'). Isto é, a cisnormatividade compreende as posições gay e lésbica, igualmente. E no caso de uma performance normativa, seu correspondente seria a homocisnormatividade ou mesmo uma lgbcisnormatividade - para ampliar o jogo de significantes.
} 
(...) uma categoria política, histórica e contingente, assim como o são o gênero, a classe social, a sexualidade ou a 'raça'. Mas não de forma isolada, pois o marcador etário e geracional dificilmente pode ser pensado sem essas intersecções. O que significa dizer que a idade organiza a vida ao conferir status de 'humanidade' em diferentes formas e condições político-culturais, no mesmo instante em que gênero e sexualidade se tornam visíveis e possíveis nesta trama discursiva (ao fixar as possibilidades para cada idade da vida) (p. 20).

Ao tomar a ideia das idades da vida como regulação e as noções de infância, juventude e velhice como também efeitos de jogos de performatividade (POCAHY, 2011), abre-se um importante campo de problematizações para a educação, especialmente na direção das cartografias do envelhecimento produzidas a partir de práticas e artefatos da cultura- das políticas públicas, às sociabilidades, passando pelas apostas curriculares para idosxs, assistência social, formação para cuidadorxs, etc.

Aliás, nenhuma categoria ou marcador é puramente um marcador em si mesmo. Ele só funciona na relação com outros marcadores, que para sua efetividade e funcionamento pressupõe performatividade. Isto é, repetições estilizadas de uma determinada prática discursiva ou não-discursiva a anteceder as nossas noções mesmas de sujeito. Foucault (2006) já nos indicara a complexa trama biopolítica por onde se insere o marcador geracional:

El otro campo de intervención de la biopolitica va a ser todo un conjunto de fenómenos, de los cuales algunos son universales y otros accidentales pero que, por una parte, nunca pueden comprimirse por entero, aunque sean accidentales, y que también entrañan consecuencias análogas de incapacidad, marginación de los individuos, neutralización, etc. Se tratará del problema de la vejez, muy importante desde principios desde siglo XIX (en el momento de la industrialización), del individuo que, por consiguiente, queda fuera del campo de capacidad, de actividad. Y, por otra parte, los accidentes, la invalidez, las diversas anomalías. En relación con estos fenómenos, la biopolitica va a introducir no sólo instituciones asistenciales (que existían desde mucho tiempo atrás) sino mecanismos mucho más sutiles, económicamente mucho más racionales que la asistencia a granel, a la vez masiva y con lacunas, que estaba esencialmente asociada a la Iglesia. Vamos a ver mecanismos más racionales, de seguros, de ahorro individual y colectivo, de seguridad, etcétera." (p. 221)

Aliado a essas problematizações, este ensaio tem um pouco a função de abrir o debate sobre a interpelação geracional, situando-a desde a produtiva noção de biopolítica que sustenta, como se observa, não somente o dispositivo da sexualidade, mas tudo aquilo o que o faz funcionar, como o marcador da idade, gênero e raça.

Não se pode dizer que exista consenso sobre isso no grupo, mas se pode afirmar 
que a forma como o grupo aborda os marcadores de gênero e sexualidade pressupõe desde sempre uma certa abertura para que essas problematizações possam ser compostas, seja de uma maneira mais sistematizada como nos estudos sobre infâncias, juventudes ou 'velhices', seja a partir do momento em que indiretamente se dá atenção a presença desses marcadores nas relações que se acompanham em pesquisa.

Esse é o caso de Claudio Ricardo Nunes (2012), orientado por Fernando Seffner, que não operou diretamente através das posições marcadas pela idade, mas ponderou a força desse marcador em algumas das práticas que observou, conforme se pode acompanhar:

(...) penso que sujeitos com mais idade e outros que estão afastados dos padrões normativos de beleza - barrigudos, baixa estatura, magricelos, peludos, obesos, mutilados - são potencialmente excitáveis e excitantes também em contextos de orgia, contagiados e contagiantes em meio a outros corpos e envolvidos em trocas sexuais. Como a cena parece sinalizar, na escuridão do ambiente, estes também são "corpos que importam" (p. 101).

A proposta deste artigo não se deita com o interesse de esgotar as tantas possibilidades de leitura sobre o marcador geracional nos trabalhos produzidos pelo GEERGE, mas aponta para o quanto determinada forma de articular gênero e sexualidade desde uma mirada muito particular de perceber a educação (em consonância com as abordagens dos Estudos Culturais) permitiu/permite a emergência de trabalhos interessados tanto no marcador geracional (como um sinalizador ou aquilo que toma maior evidência numa determinada relação ou prática social), quanto aqueles estudos que consideram esse marcador como importante em determinados movimentos no interior de uma questão.

O jogo da produção de nossos objetos de pesquisa é relacional, complexo e expansional - está aberto. Por isso não se trata de fazer um envelopamento da questão geracional nos termos de juventude, infância ou velhice, pois isso não nos convence de sua eficácia e pode, à contrapelo, deslizar para lances de objetivação. Não há, porém, experimentos nessa direção. O contrário, talvez, como o fez Nunes (2009), situando o aspecto intergeracional. $\mathrm{O}$ mais importante, acredito, é estarmos atentos de que esses marcadores podem ocupar centralidade no agenciamento de uma determinada posição de sujeito que, em outro momento, pode não ser mais tão central ou ter tamanha relevância.

Portanto, as apostas interseccionais (POCAHY, 2013) nos jogam nesse 
movimento de pensar não em unidades de representação ou mesmo na intenção de modos continuados de regulação. Ao contrário, todas as posições são contingencialmente interseccionais, se põem em modo de regulação particular de forma mais intensa em um momento/ ocasião e, noutros, por vezes, descontinuada ou em menor intensidade. Na direção das contribuições de Meyer (2013), cabe destacar: as posições e as práticas são contexto-dependentes e elas se modificam em razão contingencial. Assim, em um dado momento o marcador velhice pode ser importante em uma dada relação social, a marcar certa posição de vulnerabilidade, por exemplo; porém noutro momento ou circunstância pode até constituir-se como um privilégio ou mesmo ser usado como chave analítica para acompanhar formas de barganhar uma posição de privilégio.

Por certo algumas/alguns dentre nós já chegaram a pensar que determinadas posições são fortemente marcadas em vulnerabilidade. O risco de uma vitimização ou objetivação é potencializado quando nos apegamos à representação. Mas creio que esse argumento dos níveis de vulnerabilidade está mais para a ordem das urgências (tantas delas incontestavelmente necessárias de se abordar) e pode mesmo se colocar em um modo de agir diante do intolerável. Isso mais do que corresponder a alguma certeza de que essa posição é desde sempre uma posição segura em suas fronteiras ou formas.

De fato, muitos sujeitos têm suas vidas marcadas no jogo da abjeção e são mais prontamente expostos a toda sorte de humilhações e muitos/as deles/as exterminados/as. Eu mesmo cometi certo 'exagero' em publicação recente ao afirmar que a sociedade brasileira tutela e constrange os sujeitos na velhice (POCAHY; DORNELLES, 2017). De certa forma, sim, se pode dizer que nossa sociedade tutela e constrange as pessoas a partir do marcador da idade. E não restam exemplos de maustratos e outras violências e mesmo a representação abjeta do/a idoso/a ou as violências impetradas a crianças e jovens. Porém, não se pode dizer que em todas as dimensões de suas vidas os sujeitos ocupam posições subaltenizadas ou mesmo que tod $x \mathrm{~s} x \mathrm{~s}$ idos $x \mathrm{~s}$ vivenciem formas de opressão, que são sempre vítimas, ou mesmo que não desejam o poder ou produzam alguma norma ou mesmo que não se 'beneficiem' dessa posição. $\mathrm{O}$ jogo é complexo e situacional.

Guacira Lopes Louro (2011) ao analisar o filme Chega de Saudade, obra que tematiza a questão do envelhecimento de idosos cisgênero, nos alerta para as relações de poder a partir de gênero e sexualidade; o que vale aqui, e em certa medida lanço a aposta, também para o marcador geracional: 
Os jogos de poder que constituem as relações de gênero são mais intrincados e sutis do que parecem à primeira vista. São jogos exercidos, muitas vezes, com cumplicidade e malícia, eventualmente com violência ou consentimento, mas, sempre, com ingredientes de resistência. Como em outros jogos, as posições dos participantes podem ser transitórias e moventes; quem assume a iniciativa e o protagonismo num momento pode, em outro, se submeter. E pode se submeter para, adiante, ganhar uma nova posição. Se as formas de exercer o poder nessas relações (e em tantas outras) são, frequentemente, discretas e quase invisíveis, as formas de resistir ou de escapar à submissão são, igualmente, sutis e múltiplas. Por isso é ingênuo reduzir as relações de gênero a uma equação formada pelo binômio homem dominante versus mulher dominada. Os enredos e as estratégias desses encontros são bem mais complexos. Além disso, jogos de poder não se exercitam apenas no campo do gênero e da sexualidade, mas se dão, ao mesmo tempo, em muitos outros domínios, embaralhando os confrontos. (p. 16)

\section{O ENVELHECIMENTO NA CAMA-TRAMA DA HETERO(CIS)NORMATIVIDADE}

As análises dos primeiros estudos sobre envelhecimento, a partir da interseção com gênero e sexualidade e em crítica heteronormativa, estiveram inicialmente voltados para as sociabilidades (ou para a circulação dos sujeitos idosos em diversificados espaços), acompanhando a tendência de outros trabalhos que se debruçaram por acompanhar questões como erotismo e visibilidade de corpos desprezados na cultura.

Do ponto de vista da pesquisa na interseção com diversidade sexual e gênero os trabalhos produzidos no contexto brasileiro quase todos estiveram na direção de experiências de homens gays e alguns poucos sobre travestis. E quase nada (ainda hoje) sobre mulheres lésbicas. Os estudos de SIQUEIRA, 2008; HENNING, 2008; MOTA, 2009; PAIVA, 2009; ALVES, 2010; SIMÕES, 2011; SAMMARCO \& FROHLICH, 2011; POCAHY, 2012; BRIGEIRO \& DEBERT, 2012; KERRY \& LAGO, 2013; LACOMBE, 2013; CARDOSO, 2013; SAGESSE, 2014; HENNING, 2014; PASSAMANI, 2015, SAMARCO, 2015, SEFFNER \& DUARTE, 2015; ZAMBONI, 2015; LEITE JR, 2015 situam-se nessa composição tomando como lócus de problematização as práticas sexuais/ eróticas e as sociabilidades, mas sem muita relação ainda com aspectos de assistência ou proteção social, salvo indiretamente na articulação com saúde e violência.

O olhar para $x \operatorname{sidos} x$ s em idades e posições de fragilidade física ou funcional a partir da questão da diversidade sexual e de gênero (ou LGBT), diferente dos trabalhos 
de pesquisa e intervenção social com idosos/as cisgêneros e heterossexuais, é ainda um grande desafio na pesquisa brasileira. Nossos estudos ocupam-se em muito sobre xs idosxs jovens (ou não aplacados por contingências funcionais/ fisiológicas, cognitivas e/ou de mobilidade). Todavia, a partir do momento em que sinais de vulnerabilidade e precariedade funcional se evidenciam, como muitxs outros sujeitos na sociedade, nós (na pesquisa) também nos afastamos da velhice.

A revisão de Carlos Eduardo Henning (2017) sobre a pesquisa em contextos de países do hemisfério norte nos permite acompanhar um pouco dessa tendência, marcada efetivamente por um contexto de proteção social e de trato com a temática LGBT distintos do caso brasileiro. Os movimentos iniciais da pesquisa estadounidemse, afirma Henning (op. cit.), contestavam os estereótipos negativos acerca do envelhecimento gay e, posteriormente, movimentam-se em crítica e desconstrução dos estereótipos negativos e a pluralidade de sujeitos, como lésbicas e trans. O que parece se aproximar um pouco do nosso movimento atual. Porém, o passo dado no contexto supracitado, a partir dos anos 1990, com a discussão em torno de direitos e assistência social a idosxs, é ainda um desafio para a pesquisa e a intervenção social brasileira. Em que pese os questionamentos sobre políticas públicas e direitos estarem presentes na agenda dos movimentos LGBT no país, o envelhecimento ainda constitui sujeito invisível na maior parte das agendas políticas e culturais.

Nos estudos realizados no GEERGE não fugimos à regra. Muito embora nossos trabalhos transversalmente operem com elementos de políticas públicas, ainda à época dessas produções (até 2012), estivemos mais próximos aos registros da contestação das representações abjetas e da produção de pedagogias culturais do que propriamente mobilizados pela assistência ou outro movimento de problematização mais intensa sobre políticas públicas e sociais.

Ao operar com sociabilidades de idos $x$ s, através de bailes da terceira idade e de grupo de aposentação (ALVARENGA, 2006, e 2012), gays nas saunas (POCAHY, 2011) ou em grupos de conversa não institucionais (DUARTE, 2013), no caso desses dois últimos trabalho, o foco de maior interesse não esteve para a relação com políticas públicas e outras institucionalidades da cidadania, muito embora seja a precarização das políticas e reconhecimento o que define os objetos / problemas dessas pesquisas.

Cabe destacar que nos trabalhos de Alvarenga (2006; 2012) a preocupação com as políticas publicas já ocupa lugar de destaque, muito provavelmente porque o reconhecimento do envelhecimento para sujeitos cisgênero e heterossexuais se constitui 
de fato 'realidade' social. Muito embora, como se depreende do estudo do autor, a marca heteronormativa incida fortemente sobre a constituição da experiência desses sujeitos, ampliando o escopo analítico.

Destarte os limites impostos pela hetero(cis)normatividade, idosas cisgênero em grupos de preparação para aposentadoria ou mesmo em bailes de terceira idade, grupos de homens gays (e outros homens que fazem sexo com homens) e sociabilidades em saunas experimentam algo da experimentação de si através de espaços-tempos privilegiados igualmente para problematizar as pedagogias de gênero e da sexualidade (LOURO, 2001). Igualmente, e como poderemos perceber logo a seguir, esses espaços se constituem como importantes produtores de pedagogias do envelhecimento e intergeracionalidades. Dissidências e novas pedagogias emergem nessas experiências que acompanhamos.

Os trabalhos de Luiz Fernando Calage Alvarenga (op. cit.), fisioterapeuta de formação, atualmente professor na Escola de Educação Física/ESEF-UFRGS e vinculado ao PPG Ensino em Saúde, foram os primeiros a movimentar no GEERGE a problematização sobre o envelhecimento, gênero e sexualidade. Orientado por Dagmar Estermann Meyer, Alvarenga produziu dissertação e tese de doutorado sobre a temática. $\mathrm{Na}$ dissertação intitulada Flores de plástico não morrem?: educação, saúde e envelhecimento, o pesquisador buscou problematizar movimentos de representação no cotidiano de uma prática de promoção da saúde de idosas.

O mapeamento de representações, associado aos sentidos que suas interlocutoras atribuíram a essas marcas de poder, possibilitou ao pesquisador visibilizar alguns dos atravessamentos de gênero nessas práticas de promoção da saúde. Ao dimensionar um movimento discursivo que aponta para outros significados em torno das práticas sociais e de lazer voltadas para sujeitos da terceira idade, a pesquisa redimensiona, segundo os termos do próprio autor, os sentidos e usos das práticas de saúde (ALVAREGA, 2006).

Com a tese A arte de envelhecer ativamente: articulações entre corpo, gênero e sexualidade o pesquisador dá sequência às investigações, ainda em diálogo com mulheres cisgênero e heterossexuais (ALVARENGA, 2012). Igualmente inspirado nas apostas pós-estruturalistas presentes no trabalho de Michel Foucault a pesquisa avança tomando como lócus privilegiado as práticas de cuidado de si. Alvarenga (op. cit.) elabora em suas análises algumas unidades temáticas. A primeira delas toma a articulação entre processos de objetivação/ subjetivação mediada pelo jogo das representações da juventude como um ideal a ser perseguido e aprendido 
continuamente. Outra entrada do trabalho corresponde ao exercício da sexualidade em correspondência à saúde como indicador de uma vida saudável. Esse imperativo opera em novas aprendizagens. E, por fim, e em direção não oposta, a repercussão das ist/hiv e aids no horizonte dessas aprendizagens se configura como uma outra baliza ética na subjetivação dessas mulheres.

Assim como em sua dissertação o pesquisador opera em campo a partir de sociabilidades, apostando em um trabalho em inspiração etnográfica. Na tese ele se dirige a um grupo de preparação para a aposentadoria. No caso anterior, a pesquisa de mestrado, o trabalho envolve participantes de bailes da terceira idade. O que implica em uma produtiva reflexão sobre os múltiplos espaços-tempos que tanto disputam os significados sobre o corpo, o gênero e a sexualidade quanto produzem em novos modos de pensar problematizar o corpo em intenso investimento erótico. Isto é, somos também dotados de algum capital erótico na economia dos prazeres por onde nos embrenhamos (em pequisa). Essa dimensão é mais bastante evidente em meu trabalho de doutorado, onde meu próprio corpo é ele também sujeito que participa ativamente do campo produzindo afectos e perceptos - perguntando, aproximando, afastando.

Em minha pesquisa Pocahy (2011), Entre vapores e dublagens: dissidências homo/eróticas nas tramas do envelhecimento, operei em outra rota de investigação no GEERGE. Apoiado igualmente nas problematizações foucaultianas, fortemente aliançadas ao trabalho de Judith Butler, e abordando o envelhecimento como categoria política, assim como o considera(va)m meus colegas de grupo de pesquisa, destaquei a produtividade dos jogos performativos e da abjeção como elementos que balizam as experiências de homens idosos na cama/trama homoerótica e nas formas de reconhecimento social. A aposta do trabalho sinalizou que mesmo que os sujeitos implicados nesses jogos de poder não tenham a intenção de produzir uma crítica às normas, as cenas produzidas (em uma estilização de si) nesses espaços de sociabilidade nos pareceram produtivas para compreender a hétero e a homonormatividade como regimes discursivos que trabalham na produção de uma cultura hetero/sexista e 'velhicista', bem como a estourar as definições de homoerotismo tuteladas pelo amor romântico, fortemente influenciador de algumas experimentações da homossexualidade.

A pesquisa foi orientada por Guacira Lopes Louro e privilegiou sociabilidades que envidenciam algo das formas de contestação à representação abjeta em torno do corpo do idoso, assim como sinalizou formas de contrato erótico tarifados (no caso da 
prostituição) ou livres e desinteressados financeiramente, mas não submetidos ao regime romântico. Para isso, a pesquisa movimentou-se em redes de sociabilidades eróticas em saunas e clubes que se organizavam em torno de clientes idosos e de seus admiradores. A tese ensaia ainda homologias ao contexto francês, a partir da experiencia de estágio doutoral (doutorado sanduíche), em Lyon $\mathrm{Na}$ Universidade Lyon 2 estive sob a supervisão de Rommel Mendes Leite (in memoriam), pesquisador influente no campo dos estudos sobre (homo)sexualidade e aids. A pesquisa em território europeu acompanhou as sociabilidades e os contextos de produção de conhecimento na intersecção (homo)sexualidade e envelhecimento, considerando a força da política de identidade que marca cada país, região, lugar e os sujeitos que ali se constituem. No contexto francês a forte associação dos sujeitos idosos a um certo estilo (forjado no interior das comunidades gays) reforça a representação de masculinidade viril, especialmente a partir da figura dos bears ou lenhadores. O caso brasileiro é distinto e, embora tenha igualmente movimentos de aproximação (cultura urso), oferece um horizonte muito mais amplo nas experimenrações da sexualidade e estaria, foi minha aposta, menos 'aderente' aos processos identitários.

Ainda na esteira dos trabalhos de tese e dissertações produzidos no GEERGE destaca-se o estudo de Gustavo Duarte, graduado em Educação Física e atualmente professor da Universidade Federal de Santa Maria, junto ao curso de Dança. O pesquisador foi orientado por Fernando Seffner e tem sua tese intitulada O "Bloco das Irenes" : articulações entre amizade, homossexualidade(s) e o processo de envelhecimento. A pesquisa de Duarte (2013) teve como foco a questão do "assumir-se" (coming out) e as articulações entre o processo de envelhecimento e a questão da amizade como uma política de estilização da existência. Trabalho em perspectiva pósestruturalista e dos estudos culturais, a tese discute o tensionamento dos processos de subjetivação mediados pelas políticas de identidade e as respostas que alguns sujeitos produzem coletivamente. O grupo analisado por Duarte surgiu iniciamelmente em uma organização não governamental, mas migrou para o espaço de discussão privada como um elemento crítica e/ou distanciamento das agendas do movimento social.

Esse trabalho aponta ainda para a produção de uma erótica balizada por códigos morais que indicavam forte tendência homonormativa em alguns lances no jogo do comming out operados por seus interlocutores e nos desejos e preocupações para o reconhecimento. Entre as potentes apostas da pesquisa encontra-se a noção de ética da amizade, teorização que vem no rastro das problematizações foucaultianas. Na 
abordagem do trabalho a amizade se constituiu para os sujeitos da pesquisa como um dos modos pelos quais determinados modos de viver a velhice na interpelação da homossexualidade vão se configurando, fortalecendo os sujeitos em suas experimentações da sexualidade no dentro-fora do armário.

Outros desafios na pesquisa sobre envelhecimento foram produzidos por Dagmar Estermann Meyer e Edvaldo Couto (2011) em uma discussão sobre a juvenilização dos corpos idosos, face ao movimento de ampliação da longevidade indicado pela demografia nacional. Ao articular gênero e sexualidade ao envelhecimento, a pesquisadora e o pesquisador (à época vinculado ao GEERGE em um estágio pós-doutoral) problematizam discursos e representações do rejuvenescimento a partir de tecnologias em saúde como forma de mediar os efeitos do prolongamento da vida:

Nesse âmbito tem-se investido, então, em um processo de ressignificação em que a velhice vem sendo associada, crescentemente, com vida ativa, saúde, erotismo e felicidade. Desencadeia-se um processo de gerenciamento da velhice no qual pessoas mais velhas passam a ser concebidas como um segmento de mercado ao qual se direciona o consumo de determinados produtos e técnicas múltiplas para o cuidado de si, sob a lógica do turbinamento, do rendimento corporal e do prazer. Agora, juventude, saúde e bem-estar são também commodities e podem ser compradas pelo sujeito que, tendo deixado de ser jovem, quer viver mais e melhor.

Com essa abordagem Meyer e Couto (2011) nos oferecem importante reflexão sobre a idealização do corpo jovem. O que já ponderei em minha pesquisa, pois ao mesmo tempo em que se celebra a juventude, se opera certa contradição face aos corpos jovens, na medida em que em seus corpos são saturados de regulações e tutela. $\mathrm{O}$ argumento de Meyer e Couto (op. cit.) encontra-se ainda com as apostas de Guita Grin Debert (1997):

A característica marcante deste processo é a valorização da juventude, que é associada a valores e a estilos de vida e não propriamente a um grupo etário especifico. A promessa da eterna juventude é um mecanismo fundamental de constituição de mercados de consumo. As oposições entre o 'jovem velho' e o 'jovem jovem' e entre o 'velho jovem' e o 'velho velho' parecem ter se constituído em formas privilegiadas de estabelecer laços simbólicos entre indivíduos, em um mundo em que a obliteração das fronteiras entre os grupos é acompanhada de uma afirmação, cada vez mais intensa, da heterogeneidade e das particularidades locais. (p. 125).

$\mathrm{Na}$ direção de tensionamentos às fronteiras geracionais (ou o que se passa nelas), conforme destacado por Debert (op. cit.), Guacira Lopes Louro (2011) ensaia através de uma cartografia fílmica a eroticidade marcada e marcando corpos de sujeitos 
idosos. A partir de Chega de Saudade, filme Laís Bodanski (2008), a pesquisadora orquestra análise que articula gênero, sexualidade e envelhecimento, sem concessões (representacionais) ou vitimização. Ela afirma:

O baile (ou o filme do baile) é um recorte dos jogos imprevisíveis e plurais que se dão entre os sujeitos, não mais do que isso. Pode servir como uma espécie de vitrine que exibe e convida a ver algumas coisas ao mesmo tempo que leva a imaginar outras tantas. Aqui, a heteronormatividade, silenciosa e naturalizada, é, aparentemente, reiterada por todos. As normas regulatórias trabalham performativamente para materializar a diferença sexual. Pequenas variações de comportamentos, gestos, enunciados podem até sugerir fissuras nas expectativas tradicionais do lugar do feminino e do masculino nesta cultura, mas não chegam a contrariar o imperativo heterossexual. Não nesse baile (p. 65).

Com maestria e delicadeza com as palavras, Louro (2011) entabula importante reflexão sobre a velhice encarnada nos jogos normativos, mas também das escapadas em face das interpelações injuriosas ou ali onde se tenta fixar a diferença (que, como nos incita Tomaz Tadeu da Silva: tem como função apenas diferir). Sobre as personagens do filme, afirma ainda:

Eles e elas não querem saber de cuidados, prudência, esperas. Querem viver o momento, gozar aqui e agora. Chega de saudades, parecem dizer, quando se entregam à dança e aos jogos de sedução. Talvez estejam escapando "dos constrangimentos, dos estereótipos, das normas e dos padrões de comportamento baseados nas idades", como dizem alguns estudiosos, ou experimentem a tal "descronologização da vida" que, segundo outros, seria uma característica da pós-modernidade (DEBERT, 2005). Mas se chegam a escapar das normas, é preciso reconhecer que o fazem do seu jeito, não se travestem de jovens, não os imitam, não fingem que são garotos. Suas músicas, roupas, gestos, seus namoros e até suas brigas têm seu próprio estilo. Não parecem pretender qualquer revolução, só querem "curtir" a vida. E pode ser que dessa forma estejam, simplesmente, reinventando a velhice. (LOURO, 2011, pp. 19-20)

\section{AINDA HÁ TEMPO PARA DES(A)FIAR A VELHICE. NOTAS PARA PROSSEGUIR PESQUISANDO...}

As apostas e experimentações de todos esses trabalhos (do GEERGE e aqueles com quem dialogamos em nossas pesquisas) são recuperadas aqui para sinalizar que nos constituímos como sujeitos em tantos quantos variados são os espaços-tempos por onde andamos e desde onde somos afectados. Espaços-tempos de intensa produção de diferença. Isso nos conduz a tomar a velhice não como um universal ou matéria 
condenada aos caprichos da fisiologia, mas como efeito de um conjunto de práticas de significação, como nos recorda Doll (2015):

Hoje é possível pensar em uma gama de lugares de aprendizagem, tais como a mídia, a cultura popular, o cinema, a publicidade, as comunicações de massa e as organizações políticas e religiosas (Giroux, 1995). Essas esferas produzem imagens e saberes sobre a velhice que operam como dispositivos pedagógicos (Fischer, 1997), subjetivando os sujeitos e produzindo modos de identificação e compreensão de si e do mundo. As imagens orientam expectativas, valores, percepções e comportamentos, produzindo saberes e identidades por meio dos discursos que elas colocam em circulação (p. 10).

Na mesma direção de Doll e colaboradoras (op. cit.), acredito que parte dos trabalhos aqui citados (na composição do tema do envelhecimento nas Ciências Humanas e Sociais, assim como aqueles produzidos no GEERGE) trazem consigo os desafios propostos pelas abordagens e problematizações pós-estruturalistas, especialmente sobre a emergência de um objeto e as formas de fixação da diferença sobre a qual as próprias teorizações incidem. Isso está em consonância com as ponderações de Silva (1999) que recupero de forma direta: “Ao descrever um 'objeto', a teoria, de certo modo, inventa-o. O objeto que a teoria supostamente descreve é, efetivamente, um produto de sua criação"(p. 25).

O que desejo (re)afirmar com tal argumento é que a emergência da população (de pessoas ditas velhas/ idosas) - e a significação de "velhice" estão em disputa, seus significados deslizam e é desde essa agonística por onde temos a chance de escapar de alguma medida que nos coloque em sujeição e risco - de abjeção/ objetificação / violência/ exclusão. Afinal, ao tomarmos a velhice ou envelhecimento como objeto isso não corresponde a uma obediente sujeição à cronologia forjada nos jogos biopolíticos.

A velhice ou envelhecimento pode bem ser, como afirmam muit $x$ s de noss $x \mathrm{~s}$ interlocutorxs, aquele momento-posição onde algumas normas e imperativos de sujeição afrouxam. Por certo, outras normas e formas de apreensão/ objetivação podem surgir. Mas também pode ser o tempo onde alguns ultrapassam as tantas fronteiras da vida, arriscando limites, estranhando as representações ditas normais ou esperadas para um (determinado) corpo.

A experiência cultural e política do envelhecimento assume posições e toma formas específicas de acordo com os jogos de saber-poder e as diferenças culturais de cada cultura, época e lugar. A ideia de que estamos nos tornando uma sociedade que envelhece não expõe apenas os efeitos estruturais de um suposto peso sobre o sistema 
previdenciário ou outras mazelas da racionalidade economicista. A trama do envelhecimento (brasileiro) é mais complexa do que aquela do cálculo do estatal - ou aquela da biopolítica. Por certo as inclui. E, definitivamente, incide sobre muitas de nossas apostas de pesquisa.

Nossos questionamentos no GEERGE levaram/ têm levado a pesquisas sobre como os significados de gênero e sexualidade são apre(e)ndidos-ensinados. Estamos igualmente atentxs ao fato de que o desprezo pela velhice é ensinado-aprendido no jogo da cultura e em tantas outras instâncias sociais-culturais como a escola, o cinema, as campanhas publicitárias e nas abordagens da saúde e da assistência. Mas temos igualmente constatado que desde esses lugares se produzem experimentações dissidentes e resistências. E o que se constitui sujeito (in)viável e (im)possível a partir de gênero e sexualidade hoje já não mais pode ser pensado sem que se considere o peso da idade/ ou a marca geracional.

Estou convencido de que os desafios atuais para/ com a pesquisa com o envelhecimento se articulam nessa direção e ainda mais fortemente desde a fratura ética que se estabeleceu nas últimas eleições, com a ascensão ultraconvervadora, fundamentalista e fascista, expondo ainda mais violentamente à precariedade vidas historicamente marcadas pelo racismo e pela hetero(cis)normatividade.

Destarte todos esses 'perigos' (que nos demandam operações estratégicas com identidades e representações, cálculos, políticas, etc.) creio que estamos bastante atent $x \mathrm{~s}$ aos riscos e às ciladas que a fixação da diferença no coloca. Ali mesmo onde ela pode se deitar com a noção de identidade ou ser interpelada letalmente pelas políticas do ódio, encontramos potência em um modo de agir ético-epistemológico. Nesse sentido, nossos objetos e procedimentos se afastam da representação inconteste ou da ideia do diferente. Arriscamos diferir. Como afirma Silva (2002): “A identidade é. A diferença devém”(p.66). Portanto, ao som das vibráteis cartografias da literatura: O correr da vida embrulha tudo. A vida é assim: esquenta e esfria, aperta e daí afrouxa, sossega e depois desinquieta. O que ela quer da gente é coragem.”(ROSA, 1994, p.448).

\section{REFERÊNCIAS}

ALMEIDA, Wagner; RAXACH, Juan Carlos. $3^{a}$ Idade, Homossexualidade e HIV. Rio de Janeiro: ABIA, 2013.

ALVARENGA, Luiz Fernando Calage. Flores de plástico não morrem?: educação, saúde e envelhecimento.Dissertação de Mestrado. Programa de Pós-Graduação em Educação - UFRGS, 2006. 
ALVARENGA, Luiz Fernando Calage. A arte de envelhecer ativamente: articulações entre corpo, gênero e sexualidade.Tese de Doutorado. Programa de Pós-Graduação em Educação - UFRGS, 2012.

DUARTE, Gustavo. O "Bloco das Irenes": articulações entre amizade, homossexualidade(s) e o processo de envelhecimento. Tese de Doutorado. Programa de Pós-Graduação em Educação - UFRGS, 2013.

DOLL, Johannes; RAMOS, Anne Carolina; BUAES, Caroline Stumpf Apresentação Educação e Envelhecimento. Educação e Realidade. Mar 2015, vol.40, no.1, pp.9-15

DUMARESQ, Leila. O cisgênero existe. Disponível em:http://transliteracao.com.br/leiladumaresq/2014/12/o-cisgenero-existe/ Acessado em 20 de junho de 2016.

FOUCAULT, Michel. Defender la sociedad. 1976. Buenos Aires: Fondo de cultura económica de Argentina, 2006.

FOUCAULT, Michel. História da sexualidade. A vontade de saber. 1976. Rio de Janeiro: Graal, 1997.

HALL, Stuart. Quem precisa da identidade? In: SILVA, Tomaz Tadeu (org. e trad.). Identidade e diferença: a perspectiva dos estudos culturais. Petrópolis: Vozes, 2001.

HENNING, Carlos Eduardo. Sapinhas, bibinhas e tias: sexualidade, geração e vestuário como formas sociais de distinção identitária. Revista Enfoques, Rio de Janeiro, (7), 2008, pp.18-33.

HENNING, Carlos Eduardo. Gerontologia LGBT: velhice, gênero, sexualidade e a constituição dos “idosos LGBT". Revista Horizontes Antropológicos, Porto Alegre, ano 23, n. 47, jan./abr. 2017, pp. 283-323.

LOURO, Guacira Lopes. Gênero, sexualidade e educação.Uma abordagem pósestruturalista. Petrópolis (RJ): Vozes: 1997.

LOURO, Guacira Lopes. Teoria queer: uma política pós-identitária para a educação. Revista de Estudos Feministas, 2001, vol.9, no.2, pp.541-553.

LOURO, G. Heteronormatividade e Homofobia. In JUNQUEIRA, Rogério Diniz. Diversidade sexual na Educação: problematizações sobre a homofobia nas escolas (Org.). Brasília: MEC/ Secad/Unesco, 2009. p. 85-93.

LOURO, Guacira Lopes. Chega de saudade. Entreideias, Salvador, n.19, p.11-20, jan./jun. 2011.

MEYER, Dagmar Estermann. Abordagens pós-estruturalistas de pesquisa na interface educação, saúde e gênero: perspectiva metodológica. (49-64). In MEYER, Dagmar Estermann \& Paraíso, Marlucy (Org). Metodologias de Pesquisas Pós-críticas em Educação. BH: Mazza Edições, 2014, pp.49-64.

MEYER, Dagmar Estermann; COUTO, Edvaldo. Viver para ser velho? Cuidado de si, envelhecimento e juvenilização. Entreideias, Salvador, n.19, p.11-20, jan./jun. 2011, pp.21-32.

MEYER, Dagmar Estermann. Identidades traduzidas:cultura e docência teutobrasileira-evangélica no Rio Grande do Sul. Tese de Doutorado. Programa de PósGraduação em Educação - UFRGS, 1999.

MOTA, Muro P. Homossexualidade e envelhecimento: algumas reflexões no campo da experiência. Sinais, Vitória, (1), 2009, pp. 26-51.

Nuances, Grupo pela Livre Expressão Sexual. Prazer não tem idade. Brochura. Porto 
Alegre, 2003.

NUNES, Claudio Ricardo. Trazendo a noite para o dia: apontamentos sobre erotismo, strip tease masculino, pedagogias de gênero e sexualidade. Tese de Doutorado. Programa de Pós-Graduação em Educação - UFRGS, 2012.

PAIVA, Antonio Cristian Saraiva). Seres que não importam? Sobre homossexuais velhos. Bagoas: Revista de Estudos Gays, Natal, (3), 2009, pp. 191-208.

PASSAMANI, Guilherme. Sobre memória e condutas homossexuais: problematizando a trajetória de Tom no Pantanal-MS. Equatorial - Revista do Programa de Pósgraduação em Antropologia Social da UFRN, Natal, (3), 2015, 83-102.

POCAHY, Fernando Altair. Entre vapores \& vídeos pornôs: dissidências homo/eróticas na trama discursiva do envelhecimento masculino. Estudos Feministas. Florianópolis, (20), 2012, pp. 357-376.

POCAHY, Fernando Altair; DORNELLES, Priscila Gomes. Gênero, sexualidade e envelhecimento: mapeando a pesquisa e a intervenção social LGBT no Brasil. Journal of Studies on Citizenship and Sustainability, v. 1, 2017, pp. 124-138.

POCAHY, Fernando. Entre vapores e dublagens: dissidências homo/eróticas nas tramas do envelhecimento. Tese de Doutorado. Programa de Pós-Graduação em Educação - UFRGS, 2011.

PRADO FILHO, Kleber; TETI, Marcela Montalvão A cartografia como método para as ciências humanas e sociais. Barbaroi, (38), 2013, pp. 45-49

RICH, Adrienne. Heterossexualidade compulsória e existência lésbica. Bagoas, Natal, (5), 2010, pp. 17-44.

ROLNIK, Suely. Cartografia sentimental. Transformações contemporâneas do desejo. 2006. Porto Alegre: Editora Sulina/ Editora da UFRGS, 2011.

ROSA, Guimarães. O grande sertão: veredas. Rio de Janeiro: Editora Nova Aguiar, 1994.

SABAT, Rute Francini Ramos. Filmes infantis e a produção performativa da heterossexualidade. Tese de Doutorado. Programa de Pós-Graduação em Educação UFRGS, 2003.

SAGGESE, Gustavo. Do receio de existir ao direito de conviver: reflexões e apontamentos sobre homossexualidade masculina, geração e transformações sociais. Gênero na Amazônia, Belém, (1), 2014, pp. 15-37.

SANTOS, Daniel Kerry; LAGO, Mara. Estilísticas e estéticas do homoerotismo na velhice: narrativas de si. Sexualidad, Salud y Sociedad, Rio de Janeiro, (15), 2013, pp. 113-147.

SEFFNER, Fernando \& DUARTE, Gustavo. E quando não há muito mais o que guardar no armário? Homossexualidades e processos de envelhecimento. Bagoas Estudos gays, gêneros e sexualidades, Natal, (9), 2015, pp. 57-82.

SEFFNER, Fernando. Derivas da masculinidade: representação, identidade e diferença no âmbito da masculinidade bissexual. Tese de Doutorado. Programa de PósGraduação em Educação - UFRGS, 2011.

SILVA, Tomaz Tadeu. Documentos de identidade: uma introdução às teorias do currículo. Belo Horizonte: Autêntica, 1999.

SILVA, Rosimeri Aquino. Identidades heterogêneas na contemporaneidade violenta: um estudo a partir de uma sala de aula singular. Tese de Doutorado. Programa 
de Pós-Graduação em Educação - UFRGS, 2007.

SIMÕES, Julio Assis. Corpo e sexualidade nas experiências de envelhecimento de homens gays em São Paulo. A Terceira Idade, São Paulo, (22), 2011, pp. 7-19.

SIMÕES, Julio Assis. Homossexualidade masculina e curso da vida: pensando idades identidades sexuais. In Carrara, S. [et.al]. Sexualidade e saberes: convenções e fronteiras. (415-447). Rio de Janeiro: Garamond, 2004.

SIQUEIRA, Monica. Arrasando horrores: uma etnografia das memórias, formas de sociabilidade e itinerários urbanos de travestis das antigas. Tese de Doutorado, Universidade Federal de Santa Catarina, Centro de Filosofia e Ciências Humanas, Programa de Pós-Graduação em Antropologia Social, Florianópolis, 2009.

SIQUEIRA, Monica. Na Lapa tudo é permitido! A Lapa sob o olhar e a experiência de travestis das antigas. Iluminuras, Porto Alegre, (19), 2008, pp. 1-17.

SIQUEIRA, Monica. Sou senhora: um estudo antropológico sobre travestis na velhice. Dissertação de Mestrado, UFSC, Centro de Filosofia e Ciências Humanas. PPG em Antropologia Social, Florianópolis, 2004.

SOARES, Rosângela. Namoro MTV: juventude e pedagogias amorosas/sexuais no Fica comigo. Tese de Doutorado. Programa de Pós-Graduação em Educação - UFRGS, 2005.

SOUZA, Jane Felipe. Governando mulheres e crianças - Jardins de Infância em Porto Alegre na primeira metade do século XX. Tese de Doutorado. Programa de PósGraduação em Educação - UFRGS, 2000.

TERTO-JR, Veriano. No escurinho do cinema. Socialidade orgiástica nas tardes cariocas.Dissertação de mestrado, Programa de Pós-Graduação em Psicologia PUCRJ, 1987

ZAMBONI, Marcio. Aids, longa duração e o trabalho do tempo: narrativas de homen que vivem com HIV há mais de 20 anos. Política \& Trabalho, Campina Grande, (1), 2015, pp. 69-90. 